\title{
Totem-Pole Power-Factor-Correction Converter under Critical-Conduction-Mode Interleaved Operation*
}

\author{
Eka FIRMANSYAH ${ }^{\dagger a}$, Satoshi TOMIOKA ${ }^{\dagger \dagger}$, Seiya ABE ${ }^{\dagger \dagger \dagger}$, Nonmembers, Masahito SHOYAMA $^{\dagger \dagger \dagger}$, \\ and Tamotsu NINOMIYA ${ }^{\dagger+\dagger}$, Members
}

SUMMARY This paper proposes a new power-factor-correction (PFC) topology, and explains its operation principle, its control mechanism, related application problems followed by experimental results. In this proposed topology, critical-conduction-mode (CRM) interleaved technique is applied to a bridgeless PFC in order to achieve high efficiency by combining benefits of each topology. This application is targeted toward low to middle power applications that normally employs continuous-conductionmode boost converter.

key words: PFC, Interleaved, critical-conduction-mode, totem-pole

\section{Introduction}

The interleaved version of critical-conduction-mode (CRM) boost power-factor-correction (PFC) converter is a good alternative to the renowned continuous-conduction-mode (CCM) boost PFC converter. It is composed of bridge diodes $\left(D_{b 1}-D_{b 4}\right)$ and two boost converters connected in parallel (Fig. 1) [1].

The CRM operation mode of the converter results in zero-current-switch (ZCS) turn on transition $\left(i_{S 1}\right.$ and $i_{D 1}$ of Fig. 2). Moreover, resonance between main switch parasitic capacitance and input inductor gives nearly zero-voltageswitching (ZVS) turn on transition ( $v_{S 1}$ of Fig. 2). Both conditions make efficiency of the converter very high and less pronounced by boost diode reverse recovery problem [2].

The mentioned topology also makes PFC control scheme simpler. As a first order system, the converter is relatively easy to be stabilized. Other than that, the input current of a constant turn on CRM-boost converter will automatically be proportional to its input voltage. Therefore, a low-bandwidth output voltage regulator is enough to create PFC function based on the topology [3].

However, the input current of an individual CRM-boost PFC converter looks pulsating as shown by $i_{L 1}$ and $i_{L 2}$ in

Manuscript received January 18, 2010.

Manuscript revised May 10, 2010.

${ }^{\dagger}$ The author is with the Graduate School of ISEE Kyushu University, Fukuoka-shi, 819-0935 Japan.

${ }^{\dagger \dagger}$ The author is with the SPS R\&D Division, TDK-Lambda Corporation, Fukuoka-shi, 813-0017 Japan.

${ }^{\dagger \dagger}$ The authors are with the Faculty of ISEE Kyushu University, Fukuoka-shi, 819-0935 Japan.

${ }^{\dagger}+{ }^{\dagger}$ The author is with the Energy Electronics Laboratory, Nagasaki University, Nagasaki-shi, 852-8521 Japan.

*This paper was presented at The International Telecommunications Energy Conference (INTELEC) 2009.

a)E-mail: eka@ees.kyushu-u.ac.jp

DOI: $10.1587 /$ transcom.E93.B.2250

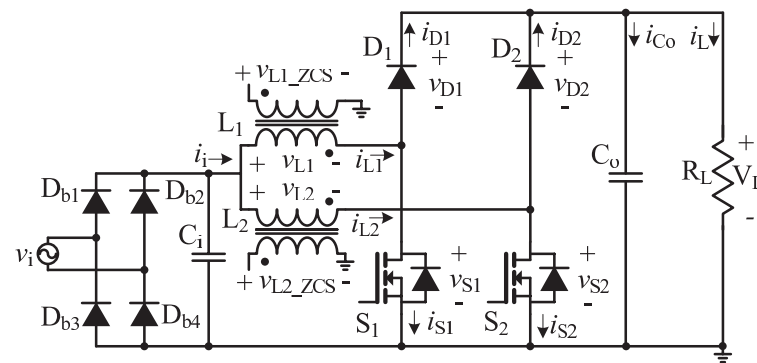

Fig. 1 A conventional CRM-interleaved boost PFC converter.

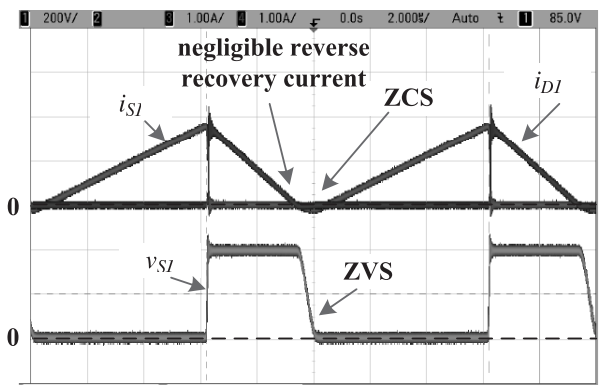

Fig. $2 i_{S}, i_{D}$, and $v_{S}$ of a conventional CRM-interleaved boost PFC converter.

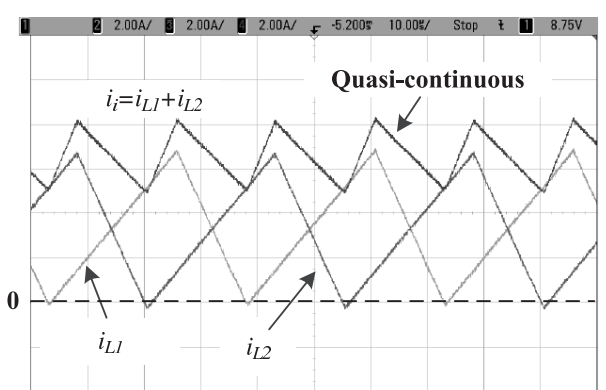

Fig. 3 Input current of a conventional CRM-interleaved boost PFC converter.

Fig. 3. This input current waveform needs significant filtering effort in order to conform EMI standard [4]. Interleaving the boost converters may reduce current spikes by producing quasi-continuous input current ( $i_{i}$ in Fig. 3 ). It is achieved by operating each converter $180^{\circ}$ out of phase [4]-[6]. With this kind of input current, EMI filtering will be less demanding [7].

A bridgeless PFC topology is another form of high ef- 


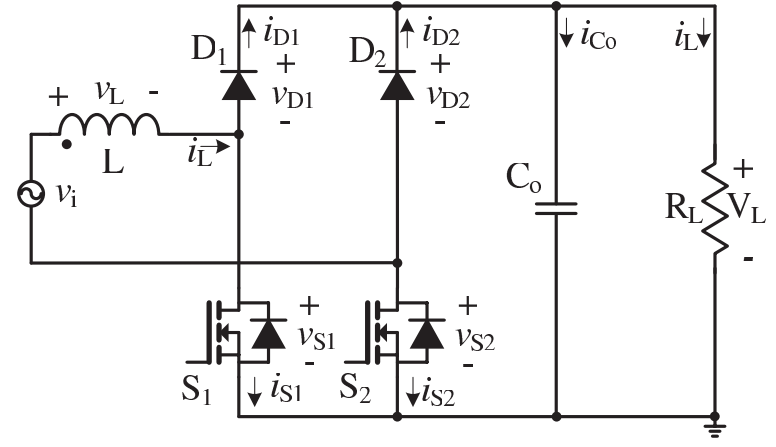

Fig. 4 Basic bridgeless PFC topology [8].

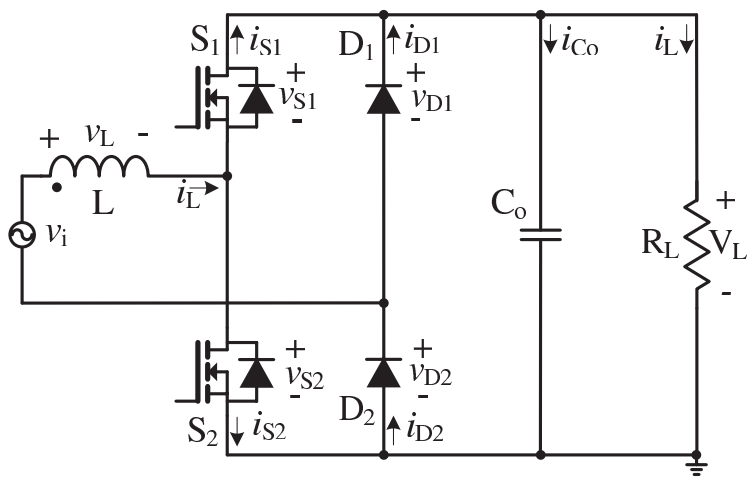

Fig. 5 Totem-pole dual-boost PFC rectifier [9].

ficient converter. It also consists of two boost converters as formerly mentioned in the CRM-interleaved boost PFC topology. However, they are connected in serial instead of parallel (Fig. 4 and Fig. 5) [8], [9].

High efficiency character of this converter is achieved by excluding bridge diodes from the PFC circuit. As a consequence, one series diode voltage drop can be saved. Theoretically, it may reclaim about $1 \%$ of conduction loss [10].

In this paper, a new bridgeless-PFC topology is proposed. The new topology works under CRM-interleaved scheme. The proposed converter gives least component and simplest circuitry compared to other possible combination of CRM-interleaved and bridgeless topology. Ideally, the absence of the bridge diodes in this PFC circuit makes its efficiency even higher compared to conventional CRM-interleaved boost PFC topology. Further details regarding schematic circuit, operation principle, equations, control mechanism, related application problems, and experimental results will be explained in the later part of this paper.

\section{Basic Building Blocks}

2.1 Problems with the Basic Bridgeless Boost PFC Topology

Circuit in Fig. 4 has larger common-mode conducted noise than conventional boost PFC topology [11]. Therefore, the circuit is impractical to recent strict noise regulation.
Moreover, interleaving a basic bridgeless PFC topology results in four boost converters: two in series to form a bridgeless PFC converter; multiplied by two to form interleaved function. It needs four switches, four diodes, and two to four inductors (depend on topology selection). Those are quite numerous numbers of semiconductors.

\subsection{The Totem-Pole Bridgeless Topology}

An interesting topology called totem-pole dual-boost PFC topology is presented in Fig. 5 [9]. This circuit is less suffer from high common-mode noise problem [12]. Moreover, when the topology is operated under interleaved scheme, it needs fewer components compared to the one based on the circuit in Fig. 4.

The totem-pole topology uses body diode of the MOSFET as its catch diode. Normally, this kind of diode has long reverse recovery time. This fact suggests that the referred circuit is only suitable for DCM (discontinuous conduction mode) and CRM operation [11].

Fortunately, this limitation does not affect too much to this research. Because, the basic circuit of CRMinterleaved topology is of course intended to work under critical-conduction-mode. With the advantage of less components requirement, this topology becomes a good candidate to be the basic topology.

\section{The Proposed Topology}

\subsection{Detailed Circuit}

Figure 6 shows schematic diagram of the proposed converter [13]. It is basically similar to the circuit of Fig. 5 with additional inductor $\left(L_{2}\right)$ and extra switch-leg $\left(S_{3}\right.$ and $\left.S_{4}\right)$ to implement interleave function.

As the proposed circuit is intended to work under CRM operation, its inductors structure $\left(L_{1}\right.$ and $\left.L_{2}\right)$ are similar to the one in Fig. 1. They are equipped with secondary winding to detect $i_{L 1}$ and $i_{L 2}$ zero-current instance.

\subsection{Operation Principle}

Related to bridgeless operation, switches in Fig. 6 can be grouped into positive-phase group $\left(S_{2}\right.$ and $\left.S_{4}\right)$ and negativephase group $\left(S_{1}\right.$ and $\left.S_{3}\right)$. The positive-phase group operates as boost-switches during positive phase of $v_{i}$. At this period, body-diodes of the negative-phase group work as the catch diode and return current is delivered by $D_{2}$. The converter operation during this stage is illustrated by Fig. 7(a).

When $v_{i}$ is in its negative phase, the opposite condition occurs. Through out this time, negative-phase group operates as the boost switches and the catch diodes are served by the body diodes of positive-phase group. Return current is handled by $D_{1}$. Figure 7 (b) depicts this condition.

Regarding the interleaved function, converter in Fig. 6 can be divided into two full functional converters. Converter 1 consists of $L_{1}, S_{1}$, and $S_{2}$ while converter 2 consists of $L_{2}$, 


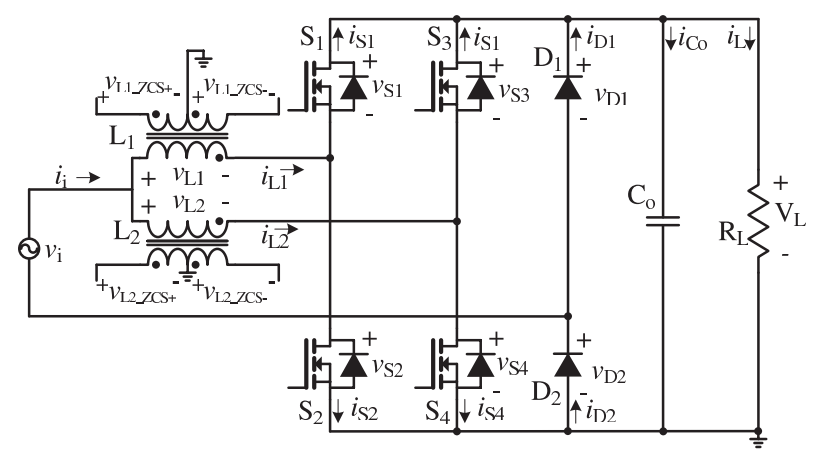

Fig. 6 The proposed converter.

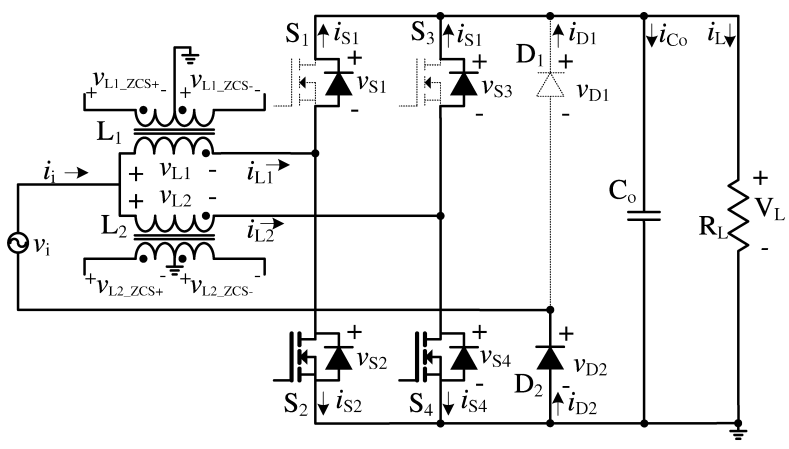

(a) During positive phase of $v_{i}$.

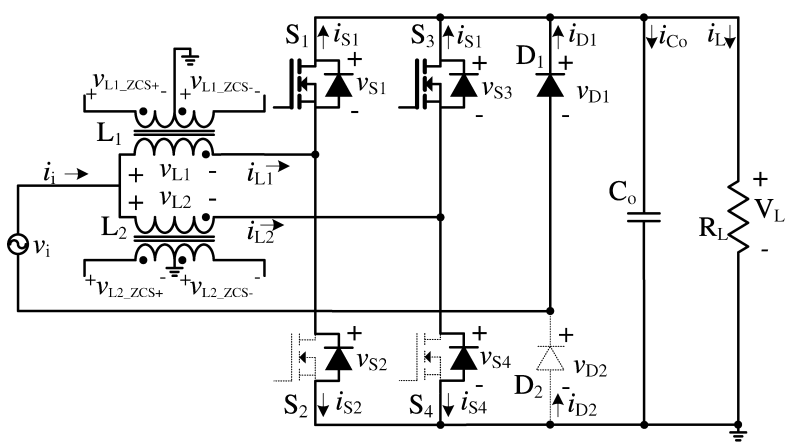

(b) During negative phase of $v_{i}$.

Fig. 7 Switch configuration of the proposed converter related to the phase of $v_{i}$.

$S_{3}$, and $S_{4}$.

Interleaved control function will make sure operation of converter 1 is $180^{\circ}$ out of phase to converter 2 in order to maximize the input current ripple cancellation. However, technique to achieve optimum interleave function is outside the scope of this paper. References [14] and [15] discuss further options related to this matter.

\subsection{Control Scheme}

Figure 8 shows the control block diagram for the proposed converter [16]. Its main part is similar to the conventional CRM-interleaved boost PFC topology. Therefore, commercially available controller for that kind of converter can be used as the core controller. However, to accommodate bridgeless nature of the proposed converter, three additional

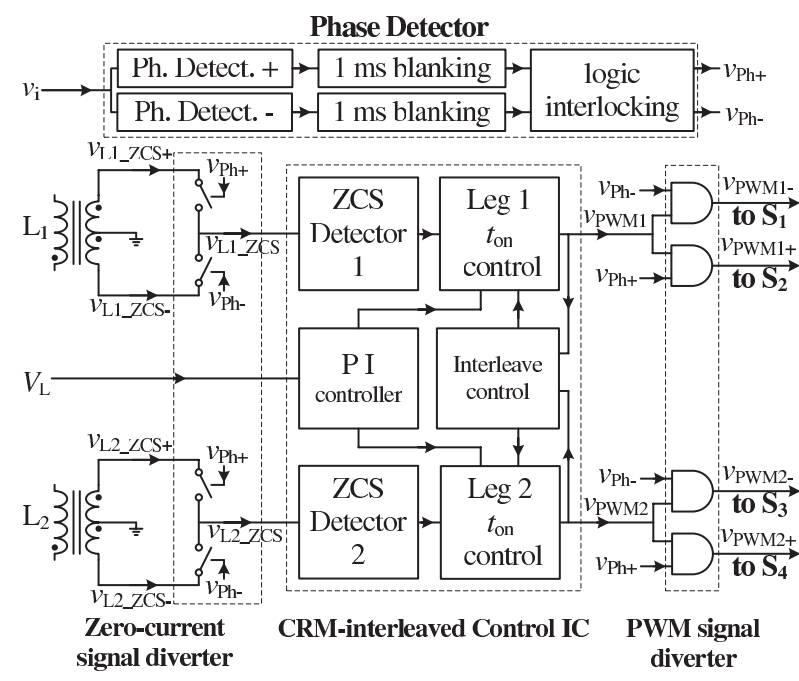

Fig. 8 Control scheme of the proposed converter.

circuits were added.

\subsubsection{Phase Detector}

A phase detector unit monitors the state of $v_{i}$. It produces two phase detection signals; $v_{P h^{+}}$and $v_{P h_{-}}$. $v_{P h_{+}}$generates logic high during positive phase of $v_{i}$, otherwise it produces logic zero. When $v_{i}$ is under negative phase, $v_{P h}$ - produce logic high. It will be zero during all other conditions.

Those two signals are generated by two independent, interlocked, and edge-blanked detection circuit to avoid phase detection mistake around $v_{i}$ zero-crossing instance. Two independent phase detection circuitry were selected in order to generate symmetrical signals among $v_{P h+}$ and $v_{P h-}$ while still accommodating slight inaccuracy in the real circuit operation. The logic interlocking mechanism avoids $v_{P h+}$ and $v_{P h-}$ to generate logic high in the same period. While, edge-blanking circuit keeps the logic stable even though oscillation occurs after $v_{i}$ zero-crossing period.

\subsubsection{Zero-Current Signal Diverter}

The CRM-interleaved boost PFC controller needs to monitor the zero-current instant time of $i_{L 1}$ and $i_{L 2}$ to determine the next switching cycle. The circuit responsible to this control function needs particular logic transition to fulfill its operation.

In order to minimize conduction loss and component cost, the detector does not incorporate resistor sensing technique or current transformer. Instead, it is implemented as secondary winding of the boost inductors [17], [18]. Voltage relation between primary winding and secondary winding can be determined as,

$$
v_{L_{S}}=\frac{n_{s}}{n_{p}} \times v_{L_{P}} .
$$

Where, $v_{L_{P}}$ and $v_{L_{S}}$ are the voltage over primary and secondary winding while, $n_{p}$ and $n_{s}$ are number of primary and 
secondary turns respectively.

Inductors of the conventional CRM-interleaved boost PFC topology is located in DC side. Therefore, the polarity $v_{L 1}$ and $v_{L 2}$ of Fig. 1 are constant. It makes the output of its secondary winding $\left(v_{L 1} Z C S\right.$ and $v_{L 2 Z Z C S}$ of Fig. 1) meet to the PFC controller logic requirement. Therefore, they can be directly connected to the controller.

However, input inductors of the proposed converter are now located in the AC side. As the consequence, phase of $v_{L 1}$ and $v_{L 2}$ of Fig. 6 alternate each time $v_{i}$ changes its polarity (Fig. 9). Two modifications are required to connect the output of $L_{1}$ and $L_{2}$ secondary winding to the controller [16],

- implement the detection winding as center-tapped winding,

- adding a zero-current signal diverter.

The center-tapped winding modification make each inductor generate complementary zero-current signals. The zerocurrent signal diverter selects which signal should be connected to the ZCS-detector of the main controller according to $v_{P h+}$ and $v_{P h-}$ logic condition. When $v_{P h+}$ gives logic high, $v_{L 1 Z C S}+$ and $v_{L 2 Z Z C S}+$ are connected to the main controller. In the other side, if $v_{P h-}$ gives logic high, $v_{L 1 Z Z C S}$ and $v_{L 2 Z C S}$ - are the one who should be connected to the main controller. The resulting waveforms of this circuit are labeled $v_{L 1 Z Z C S}$ and $v_{L 2 Z Z C S}$ (Fig. 8). The similar name of the referred waveforms to those of conventional CRMinterleaved boost PFC converter indicates characteristics similarity among them.

\subsubsection{PWM Signal Diverter}

Stated in Sect. 3.2 that proposed converter consists of positive and negative switch groups. The switch groups should

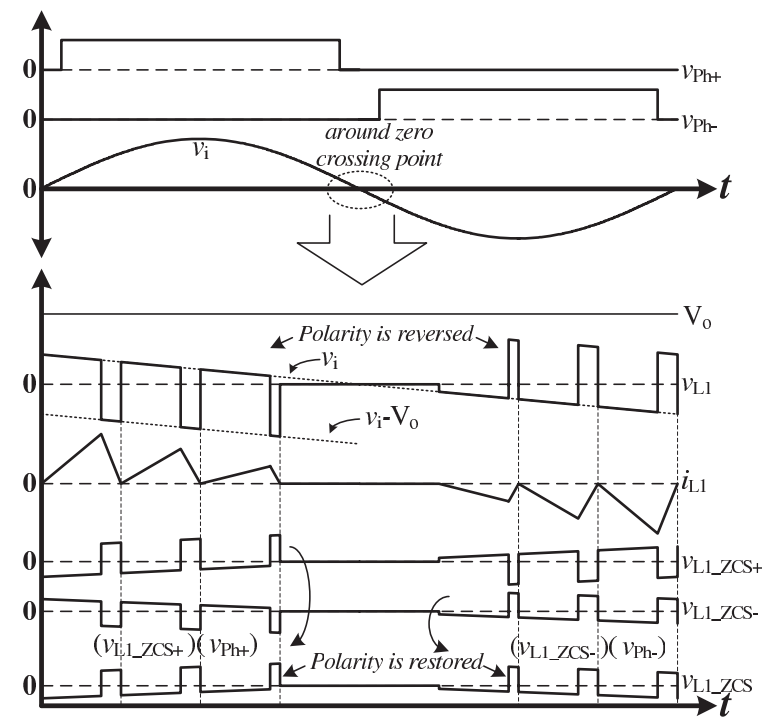

Fig. 9 Illustration of voltage waveforms generated by inductor's sense winding inside the proposed converter. be driven synchronously to the phase detection signal.

Accommodating this distinct character of the proposed converter, a PWM signal diverter is added. With this diverter, PWM signals are directed to positive-phase group ( $S_{2}$ and $S_{4}$ ) when $v_{P h+}$ is high. Otherwise, the signals will be sent to negative-phase group $\left(S_{1}\right.$ and $\left.S_{3}\right)$ when $v_{P h-}$ is high.

\section{Practical Problems}

\subsection{Reverse Recovery Current of Body Diodes}

The proposed converter utilizes MOSFET's body diodes to be used as catch diode. It should be note that body diode characteristics are not as good as a well-designed diode. This diode is actually side effect intrinsic to the MOSFET structure and is common to have ten times or more recovery charge compared to a fast recovery diode.

The higher recovery charge of the body diode makes $i_{L 1}$ of the proposed converter has significant negative current (Fig. 10(b)). This condition is not occurred in a conventional CRM-interleaved boost PFC topology (Fig. 10(a)). The negative current gives penalty toward converter efficiency as illustrated later in Fig. 13(a) of Sect. 5.

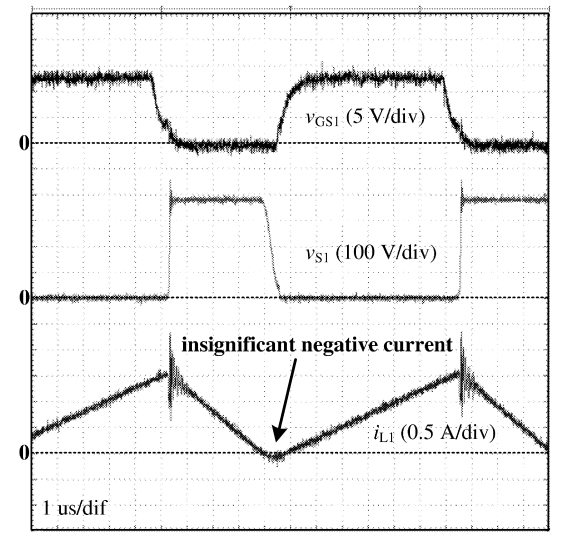

(a) Conventional CRM-interleaved boost PFC converter.

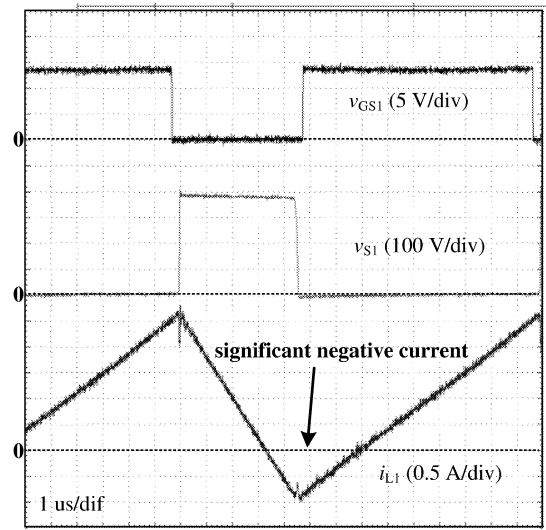

(b) The proposed converter

Fig. 10 Comparison of $i_{G S}, v_{D S}$, and $i_{L}$ in the conventional CRMinterleaved boost PFC converter to the proposed converter. 


\subsection{Voltage Ringing Near $v_{i}$ Zero-Crossing}

Every time $v_{i}$ crossing the zero-point heading to a new phase, the proposed converter enters an idle condition. Its waveforms during idle and some period after that is shown in Fig. 11. The parasitic capacitance condition during (-) to (+) phase transition is shown in Fig. 12 with:

- $C_{S n}$ is parasitic capacitance of $S_{n} ; \mathrm{n}=1,2,3,4$;

- $C_{D i}$ is parasitic capacitance of $D_{i} ; \mathrm{i}=1,2$;

- $C_{B j}$ is parasitic capacitance of the switch legs; $\mathrm{j}=1,2,3$.

Careful attention should be made on those parasitic capacitances. With condition as stated in Fig. 12, $C_{D 2}$ will be discharged through $L_{1}$ and $v_{i}$ on the first PWM signal. Here, discharging process occurs under resonant condition of $L_{1}$ and all other parasitic capacitances.

It should be noted that at this moment, $v_{i}$ is still very small and is in phase to the charge stored inside $C_{D 2}$. This creates current pulse and excites quite disturbing voltage and current oscillation as shown in Fig. 11.

The oscillation occurs in two different areas:

- $C_{S n}, C_{D i}$, and $L_{1}$ generate oscillation reverenced to the

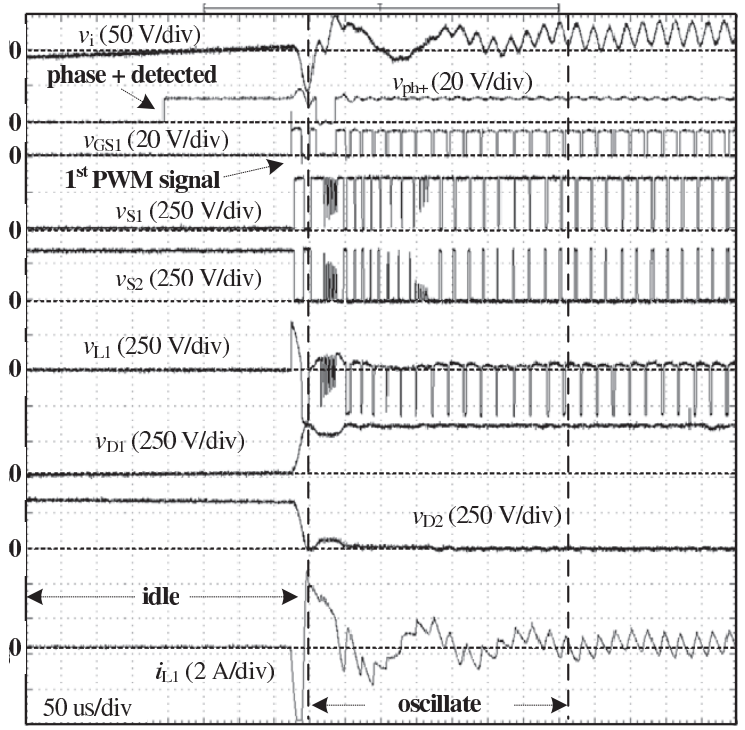

Fig. 11 The proposed topology key-waveforms during phase transition.

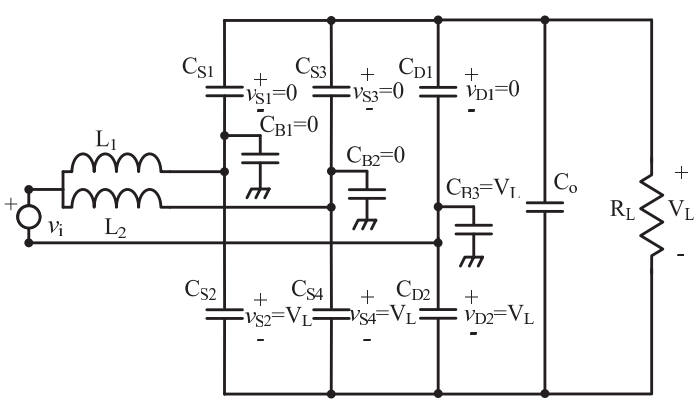

Fig. 12 Parasitic capacitaces in the proposed circuit during $v_{i}$ phase transition from - to + . neutral point,

- $C_{B j}$ and $L_{1}$ generate oscillation reverenced to the earth.

The voltage and currents oscillation result in several problems like:

- The phase detector circuit generates wrong phase detection signal. This condition may result in catastrophic event.

- Oscillation occurs among $L_{1}, C_{S n}$, and $C_{D i}$ increase differential-mode conduction noise.

- Oscillation between $L_{1}$ and $C_{B j}$ increase commonmode conduction noise.

Therefore, voltage and current ringing near zerocrossing-point of $v_{i}$ should be addressed properly in order to achieve good performance of the proposed converter.

\section{Experimental Results}

Breadboards have been built as three prototypes of the proposed converter and two types of conventional CRMinterleaved boost PFC converters. Those two types of the conventional CRM-interleaved boost topology were used to find out the effect of body-diode usage on the converter efficiency. Specifications of the converters are listed in Table 1.

Theoretically, an ideal diode will not affect the efficiency of an CRM-interleaved boost PFC converter. However, the actual circuit measurement reveals that the conventional CRM-interleaved 2, which uses body diodes as its catch diode, has the effect of efficiency decrease as shown in Fig. 13(a).

In the same figure, it can be seen that the peak efficiency of the proposed converter is about $1 \%$ higher than the conventional CRM-interleaved boost type 2 . This is close to efficiency improvement estimation stated in [10]. However, the proposed converter still cannot outperform the conventional CRM-interleaved boost type 1 which uses the ultrafast recovery diodes. The reason for this matter is due to the diode recovery characteristics as explained in Sect. 4.1.

Concerning the power-factor, three-type converters have prominent features higher than 0.96 as shown in Fig. 13(b), though the proposed one is not superior to the conventional one. Figure 14 shows that the input-current harmonic components in the proposed converter was sufficiently suppressed and complied with IEC61000-3-2 Class D limitation.

Table 1 Parameter list of the converters.

\begin{tabular}{|c|c|c|c|}
\hline & $\begin{array}{l}\text { Proposed } \\
\text { Converter }\end{array}$ & $\begin{array}{l}\text { Conventional } \\
\text { CRM- } \\
\text { interleaved } 1\end{array}$ & $\begin{array}{c}\text { Conventional } \\
\text { CRM- } \\
\text { interleaved } 2\end{array}$ \\
\hline$P_{\text {oـmax }}$ & $300 \mathrm{~W}$ & $300 \mathrm{~W}$ & $300 \mathrm{~W}$ \\
\hline$S_{1}-S_{4}$ & SPP11N60CFD & SPP11N60CFD & SPP11N60CFD \\
\hline$D_{b 1} \& D_{b 4}$ & - & RBV404 & RBV404 \\
\hline$D_{1} \& D_{2}$ & MURS360T3 & MURS360T3 & $\begin{array}{l}\text { Body-diode of } \\
\text { SPP11N60CFD }\end{array}$ \\
\hline$L_{1} \& L_{2}$ & $370 \mu \mathrm{H}$ & $370 \mu \mathrm{H}$ & $370 \mu \mathrm{H}$ \\
\hline$C_{o}$ & $200 \mu \mathrm{F}$ & $200 \mu \mathrm{F}$ & $200 \mu \mathrm{F}$ \\
\hline$V_{o}$ & $360 \mathrm{~V}$ & $360 \mathrm{~V}$ & $360 \mathrm{~V}$ \\
\hline
\end{tabular}




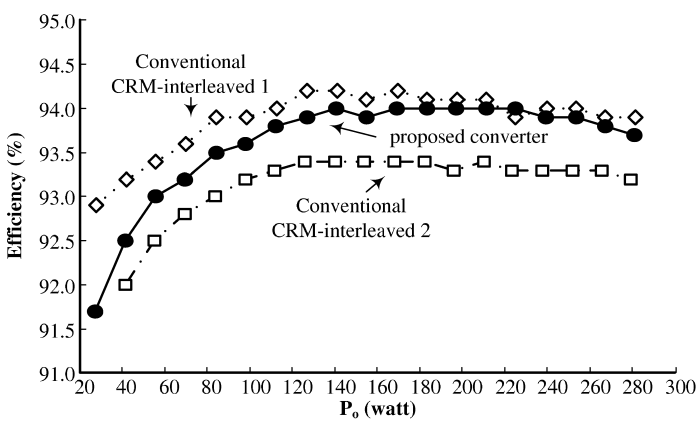

(a) Efficiency characteristics.

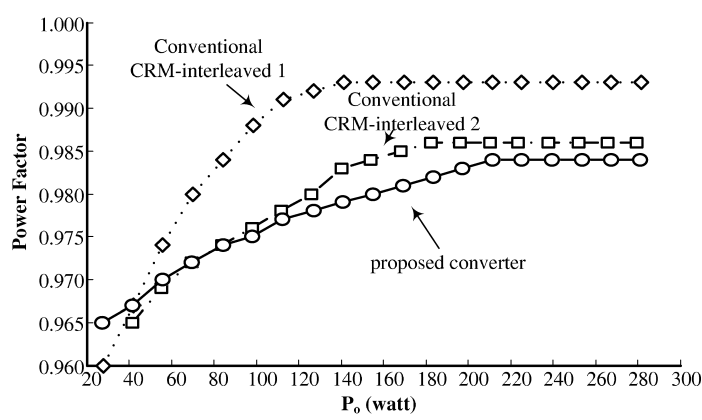

(b) Power-factor characteristics.

Fig. 13 Efficiency and power-factor characteristics of the proposed topology compared to the conventional CRM-interleaved boost PFC converter.

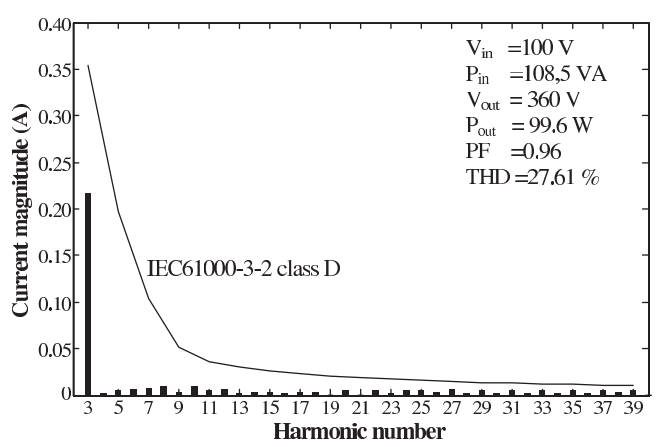

Fig. $14 i_{i}$ harmonic measurement of the proposed converter.

Figure 15 describes about current condition inside $i_{L 1}$ and $i_{i}$. It is clear that even though $i_{L 1}$ contains fast change current signal, it becomes smoother while combined with the $i_{L 2}$ and results for $i_{i}$. This is the merit of an interleaved boost technique.

\section{Conclusions}

A bridgeless CRM-interleaved boost PFC converter based on totem-pole topology has been presented. Its basic principle, detailed control scheme, implementation problems, and experimental results have been shown thoroughly. It is evident that the new topology, at recent stage, be able to pass the IEC61000-3-2 class D standard while also performing reasonable efficiency even though some practical problems are still exist. Further developments toward better results are still widely open and promising. This new topology is a

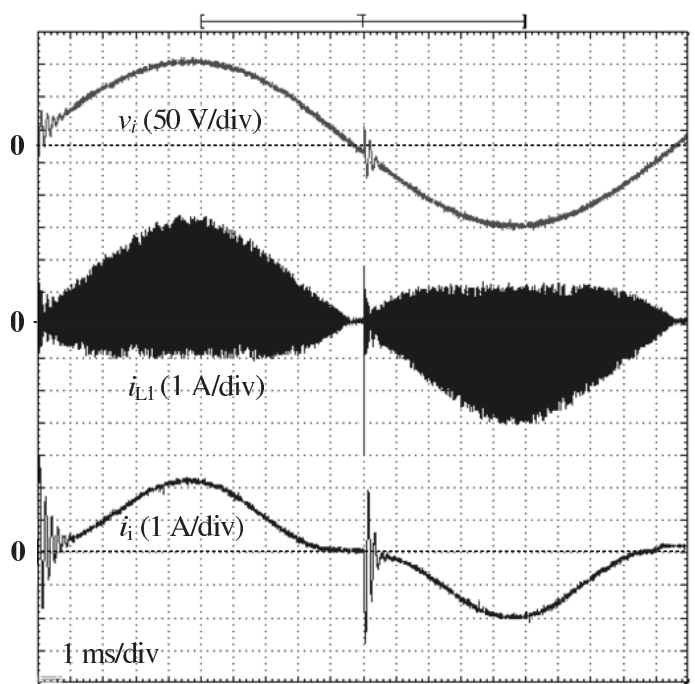

Fig. $15 v_{i}, i_{L 1}$ and $i_{i}$ waveform of the proposed converter.

good candidate toward low to middle power PFC converter.

\section{Future Work}

Further improvement of the proposed converter efficiency is important. Latest IGBT technology can be a good candidate in replacing traditional MOSFET in this area. The new generation IGBT is able to work near hundreds kilohertz switching frequency region, furthermore it does not have body diode problem of MOSFET.

Input voltage and current glitch near zero-crossing should also be addressed properly. The glitch may also give some penalties to the efficiency of the converter.

\section{References}

[1] M.S. Elmore, "Input current ripple cancellation in synchronized, parallel connected critically continuous boost converters," Conference Proceedings of Eleventh Annual Applied Power Electronics Conference and Exposition, 1996 (APEC'96), vol.1, pp.152-158, March 1996.

[2] S. Covington, "Implementing power factor correction with the NCP1608," Application Note AND8396/D Rev. 0, ON Semiconductor, July 2009.

[3] J. Turchi, "Power factor correction stages operating in critical conduction mode," Application Note AND8123/D Rev. 1, ON Semiconductor, Sept. 2003.

[4] J. Turchi, "Characteristics of interleaved PFC stages," Application Note AND8355/D Rev. 0, ON Semiconductor, Feb. 2009.

[5] M. O'Loughlin, "An interleaving PFC pre-regulator for high-power converters," Texas Instruments Power Supply Design Seminar, SEM1700, 2006.

[6] H. Choi, "Design Consideration for Interleaved Boundary Conduction Mode PFC Using FAN9611/12," Fairchild Application Note AN-6086 Rev. 1.0.4-4/22/10 2009, New Hampshire, US.

[7] J. Zhang, J. Shao, P. Xu, F.C. Lee, and M.M. Jovanovic, "Evaluation of input current in the critical mode boost PFC converter for distributed power systems," Sixteenth Annual IEEE Applied Power Electronics Conference and Exposition, 2001 (APEC 2001), vol.1, pp.130-136, March 2001.

[8] D.M. Mitchell, "AC-DC converter having an improved power factor," U.S. Patent 4412 27, Texas, Oct. 1983. 
[9] J.C. Salmon, "Circuit topologies for PWM boost rectifiers operated from 1-phase and 3-phase ac supplies and using either single or split dc rail voltage outputs," Proc. IEEE Appl. Power Electron. Conf. Expo., pp.473-479, 1995.

[10] J. Turchi, "A $800 \mathrm{~W}$ Bridgeless PFC Stage," Application Note AND8392/D Rev. 0, ON Semiconductor, Feb. 2009.

[11] L. Huber, Y. Jang, and M.M. Jovanovic, "Performance evaluation of bridgeless PFC boost rectifiers," IEEE Trans. Power Electron., vol.23, no.3, pp.1381-1389, 2008.

[12] Y. Jang and M.M. Jovanovic, "A bridgeless PFC boost rectifier with optimized magnetic utilization," IEEE Trans. Power Electron. vol.24, no.1, pp.85-93, 2009.

[13] E. Firmansyah, S. Tomioka, S. Abe, M. Shoyama, and T. Ninomiya, "A critical conduction mode bridgeless interleaved boost power factor correction," 31st International Telecomunication Energy Conference 2009 (INTELEC 2009), Oct. 2009.

[14] X. Xu and A.Q. Huang, "A novel closed loop interleaving strategy of multiphase critical mode boost PFC converters," Twenty-Third Annual IEEE Applied Power Electronics Conference and Exposition 2008 (APEC 2008), pp.1033-1038, Feb. 2008.

[15] L. Huber, B.T. Irving, and M.M. Jovanovic, "Open-loop control methods for interleaved DCM/CCM boundary boost PFC converters," IEEE Trans. Power Electron., vol.23, no.4, pp.1649-1657, July 2008.

[16] E. Firmansyah, S. Tomioka, S. Abe, M. Shoyama, and T. Ninomiya, "A critical conduction mode bridgeless interleaved boost power factor correction-its control scheme based on Commonly available controller," 8th International Conference on Power Electronics and Drive Systems (PEDS 2009) Nov. 2009.

[17] Texas Instruments, "UCC28060-natural interleaving dual-phase transition-mode PFC controller," SLUS767E, Rev., Dallas, Texas, US, Nov. 2008

[18] Fairchild Semiconductor, "FAN9611/FAN9612 interleaved dual BCM PFC controllers datasheet," Rev. 1.1.0, New Hampshire, US, 2009

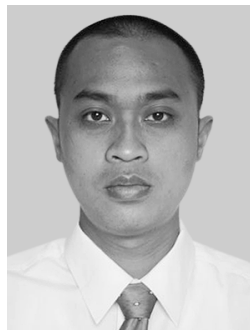

Eka Firmansyah received B.Sc. in electrical engineering from Gadjah Mada University, Indonesia in 2001. Since 2002, he joined to Electrical Engineering Dept. Engineering Faculty of Gadjah Mada University, Yogyakarta, Indonesia as a lecturer. He received M.Eng. in power electronics from Nanyang Technological University, Singapore in 2005. Recently he is pursuing for Ph.D. in Kyushu University, Japan. His research interests are in the area of high efficiency PFC and renewable energy related con-

verter.

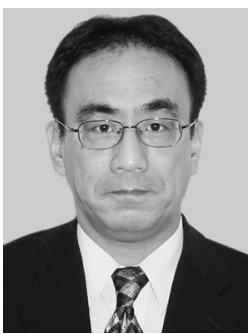

Satoshi Tomioka received the B.E. degree in electrical engineering from Tokyo Denki University, Japan in 1984. Since 1984. He is with NEMIC-LAMBDA K.K. (presently TDKLambda corporation). His main duty is research in switch mode power supply. He is currently a Senior manager of advanced development department.

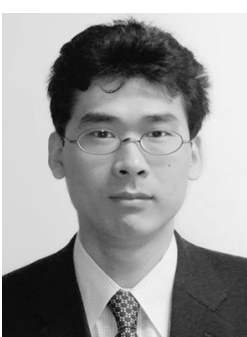

Seiya Abe received the B.E. degree from Fukuoka University, Fukuoka, Japan, in 2000 He received the M.E. and Dr.Eng. degree in Electronics from Kyushu University, Japan in 2002 and 2005, respectively. Since 2007 he has been Assistant Professor in the Department of Electrical and Electronic Systems Engineering of the Graduate School of Information Science and Electrical Engineering, Kyushu University. His research interests are DC-DC converter including Low-Voltage/High-Current Applications, Converter control and Converter system architecture. He is a member of the IEE in Japan and IEEE.

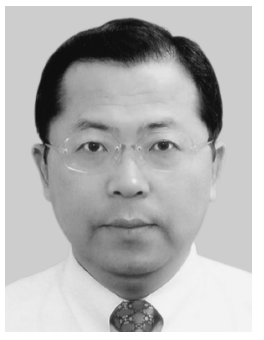

Masahito Shoyama received B.S. degree in electrical engineering and Dr.Eng. degree from Kyushu University, Fukuoka, Japan, in 1981 and 1986, respectively. He joined the Dept. of Electronics, Kyushu University as a Research Associate in 1986, and he had been an Associate Professor since 1990. Since 1996 he has been with the Dept. of Electrical and Electronic Systems Engineering of the Graduate School of Information Science and Electrical Engineering, Kyushu University. He has been active in the fields of power electronics, especially in high-frequency switching power supplies, power-factor-correctors, piezoelectric power converters, and electromagnetic compatibility (EMC). Dr. Shoyama is a member of IEEE, IEEJ, and SICE.

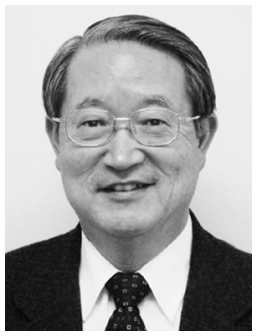

Tamotsu Ninomiya received the B.E., M.E., and Dr.Eng. degrees in electronics from Kyushu University, Fukuoka, Japan, in 1967, 1969 , and 1981, respectively. Since 1969 he has been associated with the Department of Electronics, Kyushu University, first as Research Assistant and since 1988 as Professor. Since the reorganization in 1996, he has been a Professor in the Dept. of Electrical and Electronic Systems Engineering of the Graduate School of Information Science and Electrical Engineering. He has been a specialist in the field of power electronics. He served as General Chairman in 1998 PESC, and in January 2001, he was awarded as IEEE Fellow for contributions to the development of high-frequency switching power converters. He also served as Chairman of the Technical Group on Power Engineering in Electronics and Communications of the IEICE, and an Associate Editor of IEICE Transactions on Communications. Currently he is a TDK Endowed Chair Professor at Faculty of Engineering, Nagasaki University. 